\title{
Diagnostic Approach to Synovial Sarcoma of the Head and Neck Illustrated by Two Cases Arising in the Face and Oral Cavity
}

\author{
Primali Rukmal Jayasooriya ${ }^{a} \quad$ Lindumini Nayanahari Madawalagamage $^{a}$ \\ Balapuwaduge Ranjit Rigorbert Nihal Mendis ${ }^{b}$ Tommaso Lombardi ${ }^{b}$ \\ ${ }^{a}$ Department of Oral Pathology, Faculty of Dental Sciences, University of Peradeniya, \\ Peradeniya, Sri Lanka; ${ }^{b}$ Laboratory of Oral and Maxillofacial Pathology, Division of Oral and \\ Maxillofacial Surgery, Department of Surgery, University Hospitals of Geneva and University \\ of Geneva, Geneva, Switzerland
}

Key Words

Oral cavity · Oral mucosa $\cdot$ Head and neck $\cdot$ Synovial sarcoma $\cdot$ Diagnosis

\section{Abstract}

In the head and neck region, synovial sarcomas (SS) are rare tumours. We describe the diagnostic approach to SS based on two cases which developed in a 26-year-old male in the face and in a 53-year-old female on the alveolar mucosa of the upper jaw. The demographic profile of the patients was compatible with the literature. Histopathologically, both tumours presented as unencapsulated spindle cell tumours arranged into short fascicles. Although the chromosomal translocation of $\mathrm{t}(\mathrm{X} ; 18)(\mathrm{p} 11.2 ; \mathrm{q} 11.2)$, transducin-like enhancer of split 1 (TLE-1) and SMARCB1 antibodies derived from gene expression studies are considered as the most sensitive makers to diagnose SS, these facilities were not available. Therefore, our cases were diagnosed as monophasic fibrous SS, utilizing a panel of immunohistochemical markers, including cytokeratins, EMA, BCl-2, and CD99 as positive indicators and CD34, SMA, MYO-D, and S-100 as negative indicators. PAS staining was used to identify glycogen and to exclude spindle cell carcinomas and leiomyosarcoma, while Alcian blue was used to identify myxoid ground substance and to exclude nodular fasciitis. In conclusion, SS, although rare, should be included in the differential diagnosis of spindle cell tumours of the face and oral mucosa.

(C) 2016 The Author(s)

Published by S. Karger AG, Basel 


\section{Introduction}

Synovial sarcomas (SS) are rare malignancies in the head and neck region, accounting for $1.9-3.7 \%$ of all tumours detected. These malignancies are diagnosed considering morphology, immunohistochemical findings and identification of specific translocations [1]. The diagnostic approach to SS of the head and neck region will be described, with special emphasis on how to differentiate SS from its closest mimic: spindle cell carcinoma (SpCC) [1-10].

SS is a distinctive malignancy, common in adolescents and young adults, accounting for approximately $5-10 \%$ of all sarcomas detected [1]. It predominantly occurs in the extremities, while the head and neck region is the least common site of occurrence, contributing to less than $5 \%$ of all SS detected [1,6-10]. Rarely, SS has been detected in unusual sites, such as the oral cavity, pharynx, larynx, retroperitoneum, bones, nerves, lungs, pleura, heart and kidney [8].

SS is generally classified into three major histopathological subtypes: (1) biphasic SS composed of epithelial cells arranged into glandular structures with spindle cells arranged into fascicles; (2) monophasic SS containing uniform spindle cells (monophasic fibrous) or epithelial cells (monophasic epithelioid), and (3) poorly differentiated SS characterized by the presence of spindle and/or round blue cells $[1,11]$. Other rare variants that have been described include cystic, myxoid and calcified/osseous variants [11]. Although biphasic SS is a straightforward diagnosis, monophasic fibrous and poorly differentiated SS may pose a diagnostic challenge to the pathologist, since the morphological and immunohistochemical profile of these two entities resemble many other spindle cell sarcomas and round cell sarcomas, respectively [1].

The majority of the SS, regardless of their histopathological subtype, carry the $t(X ; 18)$ translocation, involving SSX1, SSX2 or SSX4, three closely related genes from chromosome 11 and SYT gene from chromosome 18. The resultant chimeric gene has been shown to produce a transcription-activating protein SYT-SSX, which plays a major role in the oncogenesis of SS [9,12-14].

The current standard treatment for SS includes wide resection followed by polychemotherapy, with or without radiotherapy [14]. As the SS is a high-grade malignancy, 50-70\% of the cases have been shown to develop local recurrences/distant metastases. With reference to the prognostic indicators of SS, tumour size, site, histopathological subtype, tumour necrosis, and incomplete excision have been shown to carry prognostic significance $[14,15]$. No consensus has been reached regarding the role played by the type of SYT-SSX fusion and tumour grade as prognostic indicators [15].

The present report is based on two cases of SS that developed on the face and alveolar mucosa. The challenge of diagnosing SS is discussed, together with the role played by immunohistochemistry to narrow down the long list of spindle cell malignancies included in the differential diagnoses formulated based on morphology.

\section{Case Report}

Case 1

A 26-year-old male patient presented with a painful $2 \times 3 \mathrm{~cm}$ sized extraoral swelling over the right side of the face close to the lower border of the mandible that was clinically diagnosed as an abscess (fig. 1). His past medical history revealed a cystic swelling on the face, at the same location, 10 months prior to the present complaint that had been diagnosed as a ruptured epidermoid cyst. Past dental and family histories did not unmask significant findings.

At the time of the incision and drainage, the surgeon felt that there was a soft tissue component unlikely to be an abscess. Therefore, these soft tissue fragments were sent for 
Fig. 1. Extraoral presentation of the lesion (case 1).

Jayasooriya et al.: Diagnostic Approach to Synovial Sarcoma of the Head and Neck Illustrated by Two Cases Arising in the Face and Oral Cavity

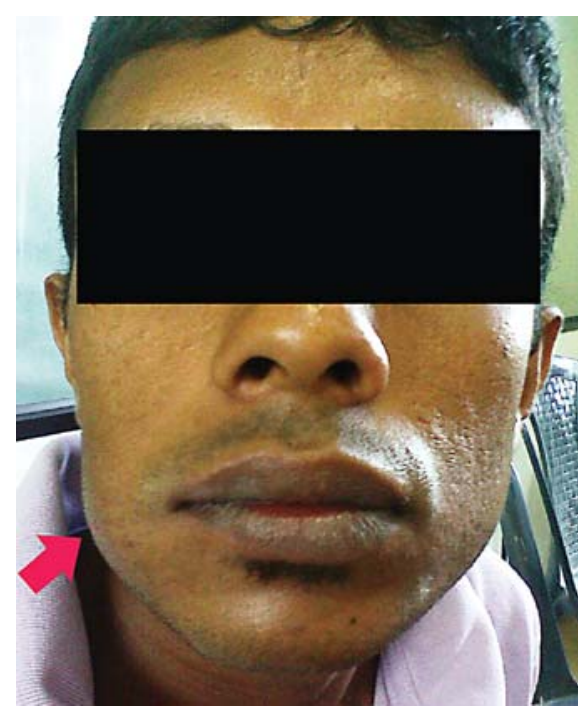

Fig. 2. A tumour composed of spindle cells showing a fascicular arrangement (case 1). HE. $\times 20$.

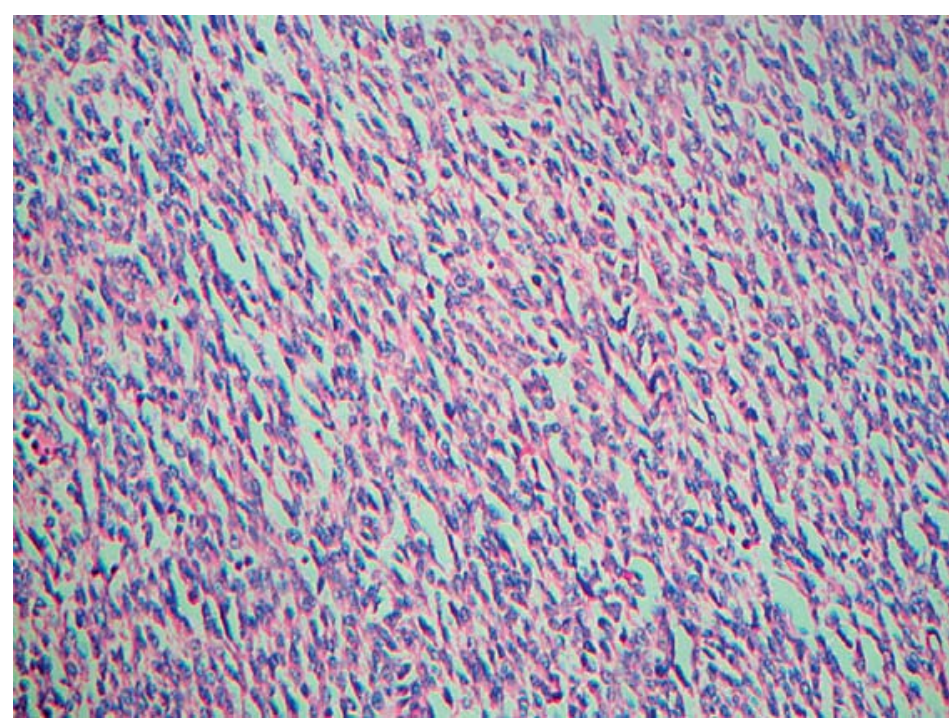

histopathological evaluation. The biopsy received consisted of several soft tissues together measuring $0.8 \times 0.8 \times 0.4 \mathrm{~cm}$ in size. The haematoxylin and eosin (HE)-stained section revealed an unencapsulated tumour composed of spindle cells with indistinct cytoplasmic borders and arranged into packed short fascicles (fig. 2). Tumour cells exhibited a moderate increase in mitotic activity (10-12/10 high-power fields). Multiple foci showed collections of necrotic cells, explaining the clinical mimicry of an abscess. The histopathological differential diagnoses, based on morphological features, were spindle cell sarcomas, such as malignant peripheral nerve sheath tumour (MPNST), SS, undifferentiated pleomorphic sarcoma (malignant fibrous histiocytoma), fibrosarcoma, leiomyosarcoma, spindle cell variant of rhabdomyosarcoma, and, considering the initial extraoral presentation, high-grade transformation of dermatofibrosarcoma protuberance (DFSP) as well as SpCC. In addition, nodular fasciitis, a lesion considered as a pseudosarcoma, was also excluded, as well as hemangiopericytoma.

Additional sections were prepared and stained with antibodies, vimentin, cytokeratin (AE1/3), EMA, SMA, BCL2, desmin, S-100, CD34, and CD99. Out of all the immunohistochemical investigations performed, tumour cells were strongly positive for vimentin, while 
Fig. 3. Focal EMA positivity in the tumour (case 1). $\times 20$.

Jayasooriya et al.: Diagnostic Approach to Synovial Sarcoma of the Head and Neck Illustrated by Two Cases Arising in the Face and Oral Cavity

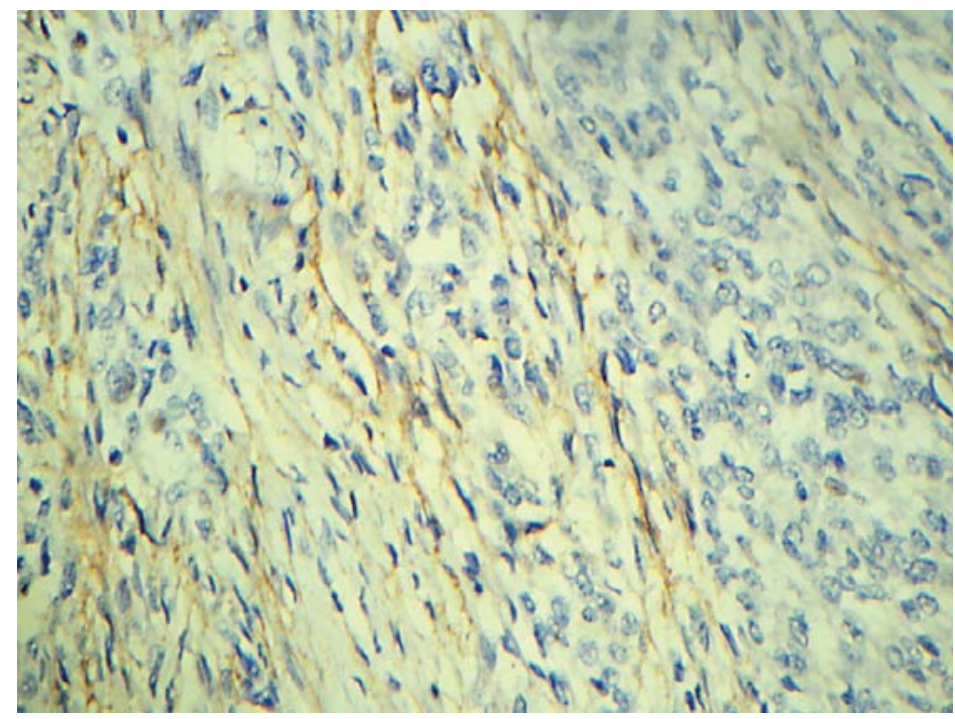

Fig. 4. Intraoral presentation of the lesion (case 2).

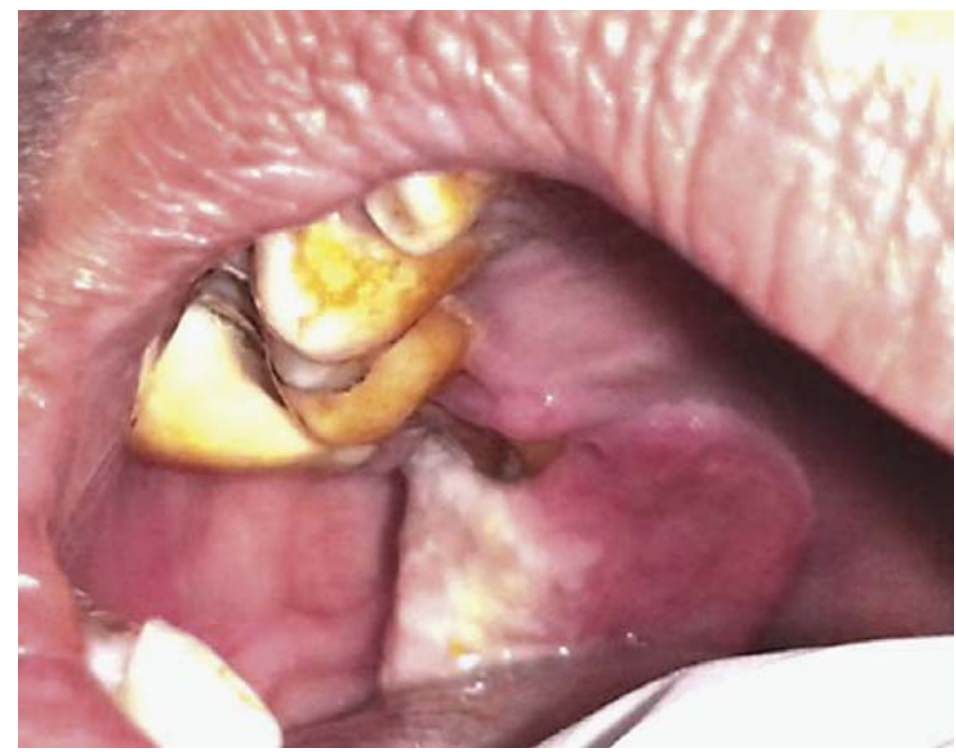

focal positivity was observed with EMA (fig. 3). All other markers were negative in tumour cells. In addition, special stains such as PAS, D-PAS and Alcian blue were also negative.

Considering the histopathological and immunohistochemical findings together with the results obtained for special stains, the lesion was diagnosed as an SS and subclassified as monophasic fibrous type. Fifteen months after the complete excision of the main lesion, the patient presented with an enlarged cervical lymph node containing a metastatic deposit of SS. The patient is disease-free at present ( 3 years after the initial diagnosis) and is on regular follow-up.

\section{Case 2}

A 53-year-old female patient presented with a painful growth on the alveolar mucosa on the right side of the posterior region of the upper jaw. The patient did not practice habits such as betel chewing, smoking or alcohol use, which are known to be associated with oral squamous cell carcinoma. Further, the patient did not have a history of being exposed to radiotherapy. On examination, extraoral facial asymmetry was present due to the poorly 
Fig. 5. A tumour composed of spindle cells arranged into fascicles (case 2). $\times 10$.

Fig. 6. Note the undifferentiated cell component present close to the non-dysplastic surface epithelium (case 2). $\times 20$.
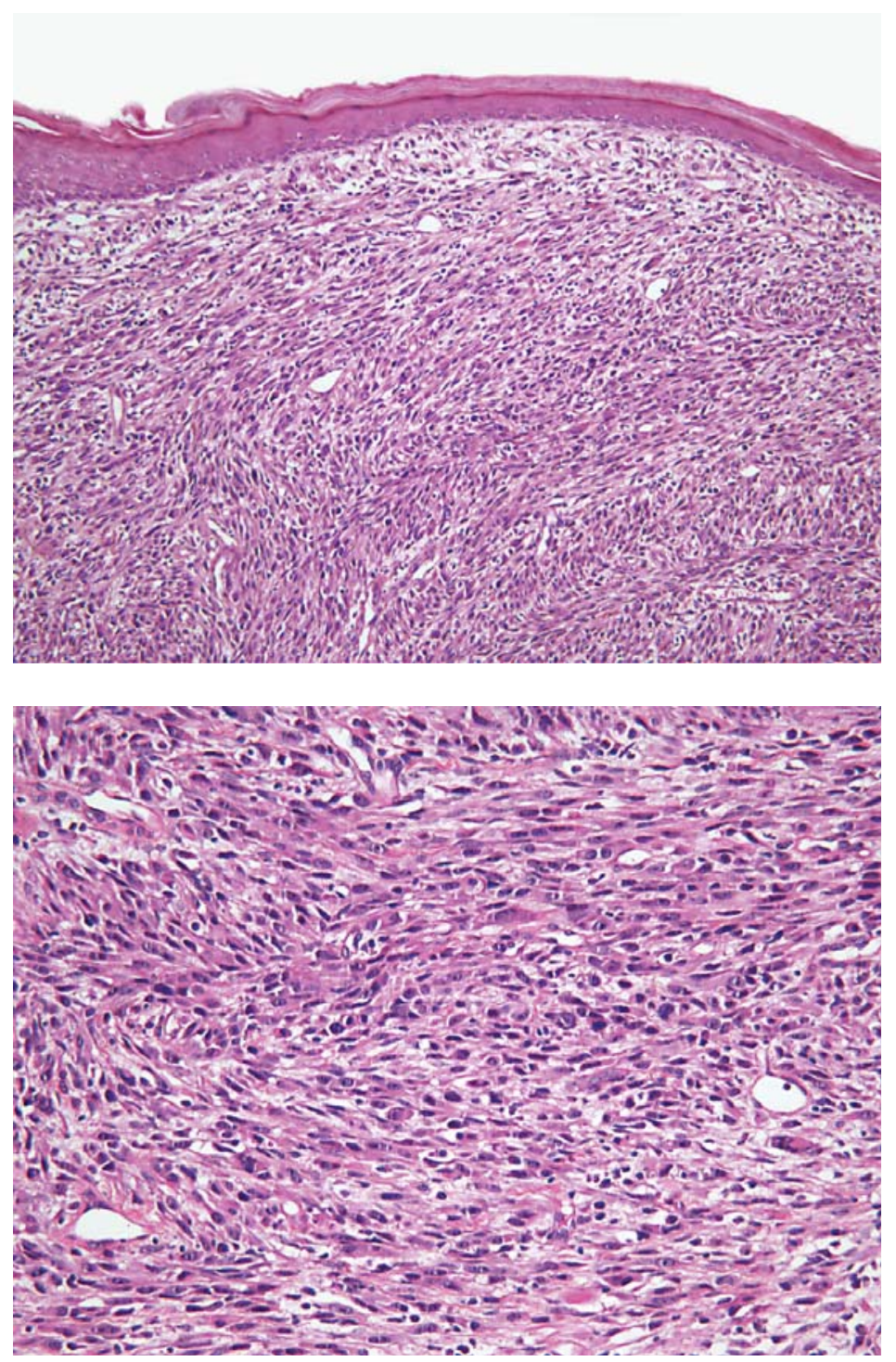

demarcated swelling on the right side of the parotid region. The area was firm and the skin was freely mobile over the swelling without any colour change. Intraorally, an exophytic growth with ulceration, $3.5 \times 2 \mathrm{~cm}$ in size, with everted, irregular margins was found on the right side of the upper buccal sulcus extending into the palatal mucosa (fig. 4). The lesion was tender on palpation and the alveolar ridge was exposed. No radiological changes except for alveolar bone erosion were observed in the radiographs.

The processed incisional biopsy under the light microscope in HE-stained sections revealed an unencapsulated tumour predominantly composed of spindle cells arranged into short fascicles. An undifferentiated cell component consisting of individual cells was also identified close to the non-dysplastic surface epithelium (fig. 5, 6). Immunohistochemical stains for CK19 (fig. 7), EMA, BCL-2 and CD99 were positive in tumour cells while SMA, S-100, and desmin were negative in tumour cells. MIB-1 staining revealed a high proliferative index (fig. 8). These histopathological features together with the immunohistochemical findings were supportive of the diagnosis of SS and subclassified as monophasic fibrous type. The patient was subsequently referred to a consultant oncologist for further management. 
Fig. 7. CK19 positivity in the undifferentiated cell component (case 2). $\times 20$.

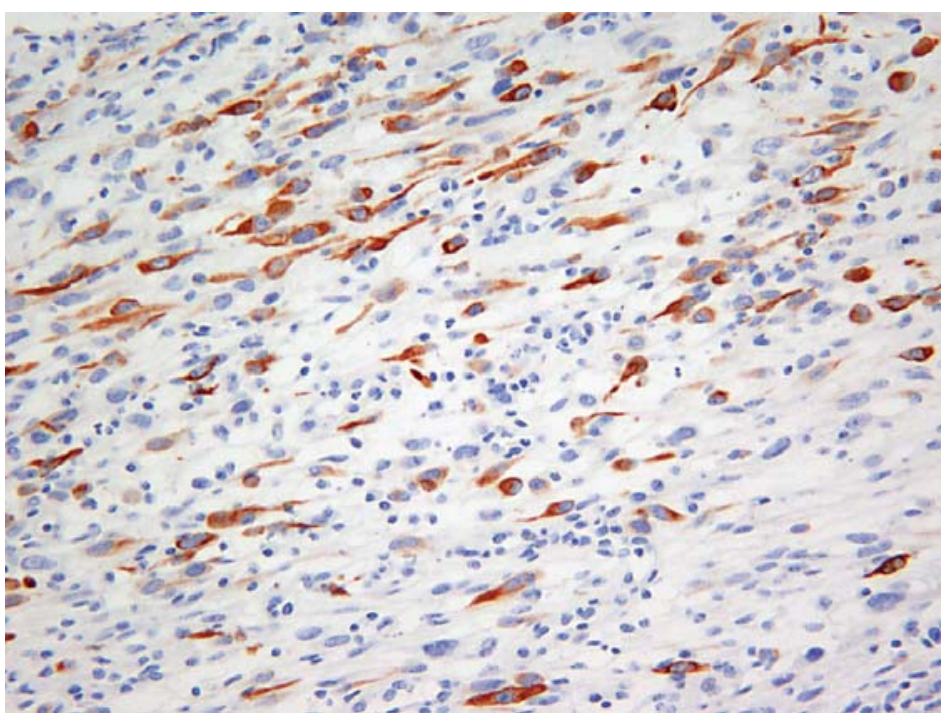

Fig. 8. MIB-1 activity of the tumour cell component (case 2). $\times 10$.

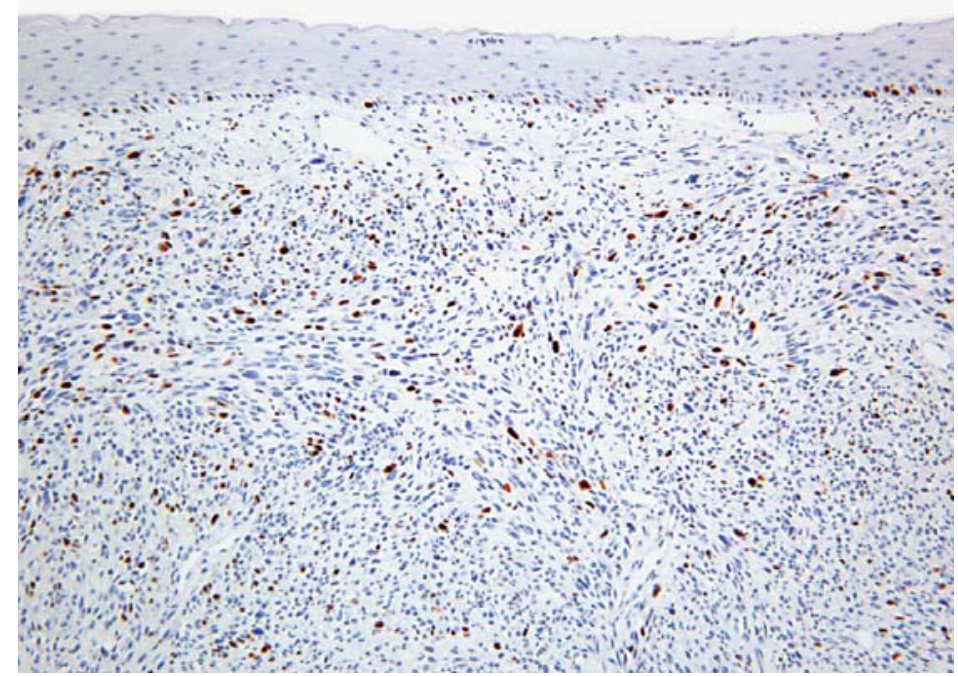

\section{Discussion}

Spindle cell malignancies such as SS and SpCC may pose a diagnostic challenge to pathologists due to infrequent presentation as well as due to the close morphological resemblance and similarities in the immunohistochemical profile of the two tumours. Although it was not possible to confirm the diagnosis of SS with transducin-like enhancer of split 1 (TLE-1), SMARCB1 and cytogenetic analysis, available resources indicate SS as the most likely diagnosis for both tumours. Table 1 shows a selected literature review-based comparison of demographic features of SS of the head and neck observed in the present cases. Accordingly, SS of the head and neck is a clinically well-defined entity, with the majority of the tumours occurring in males in the third decade of life [8, 15-17]. When head and neck sites are considered together, a preponderance of parapharyngeal spaces and hypopharynx is observed, while in relation to the face, most tumours occurred in the parotid and temporal region (that has been referred to as zygomatic, preauricular, cheek or infratemporal region) $[8,9,16-19]$. Within the oral cavity, any site can be affected, with the majority being reported 
Jayasooriya et al.: Diagnostic Approach to Synovial Sarcoma of the Head and Neck Illustrated by Two Cases Arising in the Face and Oral Cavity

Table 1. Literature review-based comparison of demographic features of SS of the head and neck with the present cases

\begin{tabular}{lll}
\hline Feature & $\begin{array}{l}\text { Literature review-based } \\
\text { findings [8, 15-17] } \\
\text { (n=69) }\end{array}$ & $\begin{array}{l}\text { Present cases } \\
(\mathrm{n}=2)\end{array}$ \\
& & \\
\hline $\begin{array}{l}\text { Age distribution } \\
\text { Mean age, years }\end{array}$ & 28.6 & 38 \\
$\quad$ Age range, years & $17-86$ & $26-53$ \\
Gender distribution & & \\
$\quad$ Male & 45 & 1 \\
$\quad$ Female & 24 & 1 \\
$\quad$ Male:female ratio & $1.9: 1$ & $1: 1$ \\
Site distribution & & 2 \\
$\quad$ Head & 22 & 0 \\
$\quad$ Neck & 31 & 0 \\
$\quad$ Unknown & 16 & \\
Histopathological subtype & & 0 \\
$\quad$ Biphasic & 19 & 0 \\
$\quad$ Monophasic & 29 & 0 \\
$\quad \begin{array}{l}\text { Poorly differentiated } \\
\text { Unspecified }\end{array}$ & 06 & unknown \\
Prognosis & 15 & \\
5-year survival & $58-100 \%$ & \\
\hline
\end{tabular}

in the jaw bones and the tongue [19-21]. Age and gender distribution of the first case is similar to the common presentation expected for SS, while in contrast to the literature this patient's lesion occurred in the face close to the lower border of the mandible, which is a relatively uncommon location for SS of the head and neck sites. The majority of intraoral SS has been reported in elderly patients, while male predilection is also less commonly observed, similar to our second patient [19-21]. However, it is essential to exclude metastatic lesions from a primary in other locations when SS is encountered in the face or oral cavity. To date, no other primaries have been identified in our patients.

SpCC, a variant of squamous cell carcinoma, was the first lesion to be considered in the differential diagnosis. According to the literature, approximately two thirds of SpCCs are biphasic tumours showing a well-differentiated epithelial component, while the minority are monophasic containing only a spindle cell component, making the differentiation from a sarcoma difficult. SpCC shows a similar demographic presentation to conventional squamous cell carcinoma occurring predominantly in elderly male patients [2, 3]. Unlike conventional squamous cell carcinoma, the majority (50-60\%) of SpCC of the oral cavity may occur as exophytic masses [2, 3]. However, according to Viswanathan et al. [3] and Thway and Fisher [4], the presence of surface epithelial dysplasia, squamoid differentiation within the tumour, tumour giant cells, collagenous stroma, a high degree of anaplasia and atypical mitoses are all features that should more strongly suggest a diagnosis of SpCC. However, none of these features were prominently present in our case, which led us to explore the possibility of diagnosing the lesion as SS. In addition, the majority of SpCC have shown positivity to epithelial markers, with aberrant expression of mesenchymal markers. Thway and Fisher [4] and Ito et al. [5] highlight the fact that epithelial markers are more diffusely positive in SpCC than in SS. In the present cases, only focal cytokeratin or EMA positivity was seen, which is more compatible with the diagnosis of SS. Table 2 presents the information that was used to diagnose the present cases with SS [1-24].

Malignant lesions with spindle cells arranged into fascicles were considered, as both tumours discussed in the case reports showed fascicular arrangements. MPNST is a high- 
Table 2. Clinicopathological comparison of SS and SpCC with the present cases

\begin{tabular}{|c|c|c|c|c|}
\hline Feature & $\operatorname{SpCC}[2,3]$ & SS $[1,4-24]$ & Case 1 & Case 2 \\
\hline \multicolumn{5}{|l|}{ Demographic features } \\
\hline Habits & $\begin{array}{l}\text { Betel chewing, smoking, alcohol } \\
\text { use for oral lesions, radiotherapy }\end{array}$ & Unknown & Occasional smoker & $\begin{array}{l}\text { No history of } \\
\text { relevant } \\
\text { habits }\end{array}$ \\
\hline Age & 5th-6th decade & $\begin{array}{l}\text { Predominantly in young adults, } \\
90 \% \text { occur before } 60 \text { years of age }\end{array}$ & Young adult & 6th decade \\
\hline Gender & Male predilection (M:F 3:1) & Slight male predilection & Male & Female \\
\hline \multicolumn{5}{|l|}{ Pathological features } \\
\hline Squamoid differentiation & Present in $50-80 \%$ of tumours & Absent in monophasic SS & Absent & Absent \\
\hline Polypoid configuration & Present in $90 \%$ of tumours & Absent & Absent & Absent \\
\hline $\begin{array}{l}\text { Surface epithelial } \\
\text { dysplasia }\end{array}$ & Present & Absent & Absent & Absent \\
\hline Tumour giant cells & Present & Absent & Absent & Absent \\
\hline Collagenous stroma & Present & Minimal stroma in monophasic SS & Absent & Absent \\
\hline High degree of anaplasia & Present in $70-90 \%$ of tumours & Absent & Absent & Absent \\
\hline \multicolumn{5}{|l|}{ Immunohistochemistry } \\
\hline Pan-cytokeratin & $\begin{array}{l}\text { Diffuse positivity in } 50-70 \% \text { of } \\
\text { tumours }\end{array}$ & Focal positive in monophasic SS & Negative & Focal positive \\
\hline CK7/19 & Negative & Positive & Negative & Focal positive \\
\hline CK8/18 & Positive & Negative & Unavailable & Unavailable \\
\hline EMA & Positive in $17-29 \%$ of tumours & Positive in $90 \%$ of tumours & Focal positive & Focal positive \\
\hline Bcl2 & Data unavailable & Positive in $98 \%$ of tumours & Negative & Positive \\
\hline CD99 & Data unavailable & Positive in $60 \%$ of tumours & Negative & Positive \\
\hline TLE1 & Data unavailable & Positive in $100-80 \%$ of tumours & Unavailable & Unavailable \\
\hline P63 & Positive in $30 \%$ of tumours & Negative & Unavailable & Unavailable \\
\hline Calponin & Positive in $100 \%$ of tumours & Focal positive in $30 \%$ of tumours & Unavailable & Unavailable \\
\hline Smooth muscle actin & Positive in $16-30 \%$ of tumours & Negative & Negative & Negative \\
\hline S-100 & Positive in $5-7 \%$ of tumours & Positive in $40 \%$ of tumours & Negative & Negative \\
\hline Demin & Positive in $3-18 \%$ of tumours & Negative & Negative & Negative \\
\hline SMARCB1 & Data unavailable & $\begin{array}{l}\text { Reduced expression in } 92 \% \text { of } \\
\text { tumours }\end{array}$ & Unavailable & Unavailable \\
\hline \multicolumn{5}{|l|}{ Special stains } \\
\hline PAS stain & $\begin{array}{l}\text { Positive due to presence of } \\
\text { glycogen }\end{array}$ & Negative & Negative & Negative \\
\hline Reticulin stain & $\begin{array}{l}\text { Positivity present around cell } \\
\text { clusters }\end{array}$ & $\begin{array}{l}\text { Positivity present around } \\
\text { individual cells }\end{array}$ & $\begin{array}{l}\text { Positive around } \\
\text { individual cells }\end{array}$ & $\begin{array}{l}\text { Positive } \\
\text { around } \\
\text { individual } \\
\text { cells }\end{array}$ \\
\hline FISH & Data unavailable & $\mathrm{T}(\mathrm{X}: 18)$ translocation & Not done & Not done \\
\hline
\end{tabular}

grade sarcoma composed of spindle cells containing wavy nuclei. Tumour cells, arranged into long fascicles and perivascular collars together with geographic necrosis, are other characteristic features of MPNST. In other words, MPNST shows an unequal distribution of tumour cells, with hyper- and hypocellular areas. In addition to tumour cells showing a high degree of atypia, MPNST is also sometimes associated with neurofibromatosis type I. Immunohistochemically, MPNST presents with focal nuclear S-100 positivity. However, in contrast to MPNST, the SS in our patients showed spindle cell components arranged into short fascicles. Further, the immunohistochemical finding of EMA positivity and S-100 negativity was useful to exclude MPNST [1].

Leiomyosarcoma is a morphologically distinct tumour composed of spindle cells showing cigar-shaped blunt-ended nuclei, with eosinophilic cytoplasm, arranged into long fascicles. Immunohistochemically, it is characterized by SMA, muscle-specific actin, desmin, and 
h-caldesmon positivity. The absence of the above morphological and immunohistochemical findings in the present tumours resulted in the exclusion of leiomyosarcoma. Although some leiomyosarcomas may co-express EMA, in a dot-like pattern [21], the absence of positivity with muscle markers resulted in the exclusion of this entity in our patients.

Undifferentiated pleomorphic sarcoma (previously known as malignant fibrous histiocytoma) is the most common soft tissue sarcoma of late adult life with a predilection to the retroperitoneum and extremities [1]. Out of the subtypes, storiform-pleomorphic sarcoma is the entity that was considered in the differential diagnosis of the present tumour. However, the absence of storiform arrangement as well as EMA positivity was useful to exclude undifferentiated pleomorphic sarcoma in our patients.

Spindle cell rhabdomyosarcoma of the juvenile (adolescent) type is a sarcoma that shows predilection to head and neck sites [21]. However, though the clinical presentation of this tumour is similar to the presentation of the first patient, in order to render a diagnosis of spindle cell rhabdomyosarcoma, tumour cells should stain positively to muscle markers desmin and or MYO-D (nuclear marker). Negative immunohistochemical findings were useful to exclude spindle cell rhabdomyosarcoma in our first patient.

Adult fibrosarcomas are now considered as rare tumours, diagnosed by excluding other specific spindle cell tumours [1]. Therefore, a diagnosis of fibrosarcoma requires negativity for all lineage markers except vimentin [15]. However, specific subtypes of fibrosarcoma, such as those arising in DFSP, are positive for CD34. In the present case, the absence of a storiform arrangement, and the lace-like infiltration of the tumour into adipose tissue seen in typical DFSP, together with CD34 negativity and EMA positivity resulted in the exclusion of fibrosarcoma as well as fibrosarcoma arising in DFSP.

Thus, the final diagnoses achieved for the tumours were SS-monophasic fibrous subtype. With reference to the histopathological subtype in the older literature, biphasic SS is considered as the commonest subtype [7]. However, with the availability of immunohistochemical investigations, most recently published large series of SS identify the monophasic spindle cell variant as the commonest subtype in all locations [7]. The tumour described in case 2 showed an undifferentiated cell component, which made us diagnose it as a poorly differentiated SS initially. However, Weiss and Goldblum [1] support the presence of an undifferentiated cell component in the monophasic fibrous subtype, resulting in the final diagnosis of the SS monophasic fibrous subtype.

With reference to the immunohistochemical profile of SS, TLE-1 is the most sensitive/ specific immunohistochemical marker available at present to distinguish SS from its histopathological mimics described above [23, 24]. According to Foo et al. [24], in 2011, 82\% of all subtypes of SS and 78, 79, and 91\% of biphasic, monophasic and poorly differentiated SS showed nuclear positivity with TLE-1. However, due to unavailability, we could not confirm our diagnosis with TLE-1 or SMARCB1.

All sarcomas including SS are managed using a single or a combination of treatment modalities including surgery, radiotherapy and chemotherapy. According to Harb et al. [8], patients who had received received surgery and radiotherapy showed better survival and less recurrences compared to other treatment options. Further, Mullins and Hackman [17] showed similar survival rates for SS of the head and neck and limbs.

SS has been shown to metastasize after more than 5 years of disease-free survival. Therefore, our patients will be kept under long-term close follow-up.

\section{Statement of Ethics}

Written informed consent has been obtained from each patient. 


\section{Disclosure Statement}

The authors declare no conflict of interest. No funding has been obtained for this work.

\section{References}

1 Weiss SW, Goldblum JR: Enzinger and Weiss's Soft Tissue Tumours. St Louis, Mosby, 2001, pp 1162-1177.

-2 Lewis JS: Spindle cell lesions - neoplastic or non-neoplastic?: spindle cell carcinoma and other atypical spindle cell lesions of the head and neck. Head Neck Pathol 2008;2:103-110.

-3 Viswanathan S, Rahman K, Pallavi S, Sachin J, Patil A, Chaturvedi P, D’Cruz A, Agarwal J, Kane SV: Sarcomatoid (spindle cell) carcinoma of the head and neck mucosal region: a clinicopathologic review of 103 cases from a tertiary referral cancer center. Head Neck Pathol 2010;4:265-275.

-4 Thway K, Fisher C: Synovial sarcoma: defining features and diagnostic evolution. Ann Diagn Pathol 2014;18: 369-380.

-5 Ito J, Asano N, Kawai A, Yoshida A: The diagnostic utility of reduced immunohistochemical expression of SMARCB1 in synovial sarcomas: a validation study. Hum Pathol 2016;47:32-37.

6 Al-Duraji W, Lasota J, Foss R, Mieittinen M: Synovial sarcoma involving the head: analysis of 36 cases with predilection to parotid and temporal regions. Am J Surg Pathol 2009;33:1494-1503.

7 Amble FR, Olsen KD, Nascimento AG, Foote RL: Head and neck synovial cell sarcoma. Otolaryngol Head Neck Surg 1992;107:631-637.

8 Harb WJ, Luna MA, Patel SR, Ballo MT, Roberts DB, Sturgis EM: Survival in patients with synovial sarcoma of the head and neck: association with tumour location, size and extension. Head Neck 2007;29:731-740.

-9 Pelmus M, Guillou L, Hostein I, Seirankowski G, Lussan C, Coindre JM: Monophasic fibrous and poorly differentiated synovial sarcoma: immunohistochemical reassessment of $60 \mathrm{t}(\mathrm{X} ; 18)$ (SYT-SSX) positive cases. Am J Surg Pathol 2002;26:1434-1440.

10 Fisher C: Synovial sarcoma. Ann Diagn Pathol 1998;6:401-421.

-11 dos Santos NR, de Bruijn DR, van Kessel AG: Molecular mechanisms underlying human synosvial sarcoma development. Genes Chromosomes Cancer 2001;30:1-14.

12 Ladanyi M: Fusions of the SYT and SSX genes in synovial sarcoma. Oncogene 2001;20:5755-5762.

-13 Ladanyi M, Antonescu CR, Leung DH, Woodruff JM, Kawai A, Healey JH, Brennan MF, Bridge JA, Neff JR, Barr FG, Goldsmith JD, Brooks JS, Goldblum JR, Ali SZ, Shipley J, Cooper CS, Fisher C, Skytting B, Larsson O: Impact of SYT-SSX fusion type on the clinical behaviour of synovial sarcoma: a multi-institutional retrospective study of 243 patients. Cancer Res 2002;62:135-140.

14 Krieg AH, Hefti F, Speth BM, Jundt G, Guillou L, Exner UG, von Hochstetter AR, Cserhati MD, Fuchs B, Mouhsine E, Kaelin A, Klenke FM, Siebenrock KA: Synovial sarcoma usually metastasize after $>5$ years: a multicenter retrospective analysis with minimum follow-up of 10 years for survivors. Ann Oncol 2011;22:458-467.

15 Rangheard AS, Vanel D, Viala J, Schwaab G, Casiraghi O, Sigal R: Synovial sarcomas of the head and neck: CT and MR imaging findings of eight patients. Am J Neuroradiol 2001;22:851-857.

-16 Salcedo-Hernández RA, Lino-Silva LS, Luna-Ortiz K: Synovial sarcoma of head and neck: comparative analysis with synovial sarcoma of the extremities. Auris Nasus Larynx 2013;40:476-480.

17 Mullins BT, Hackman T: Adult synovial sarcoma of head and neck: an institutional study and literature review. J Nat Sci 2015;1:e68.

18 Shmookler BM, Enzinger FM, Brannon RB: Orofacial synovial sarcoma: a clinicopathologic study of 11 new cases and review of the literature. Cancer 1982;50:269-276.

19 Mikami T, Kurose A, Javed F, Takeda Y: Detection of rare variant of SS18-SSX1 fusion gene and mutations of important cancer related genes in synovial sarcoma of the lip: gene analyses of a case and literature review. J Oral Maxillofac Surg 2015;73:1505-1515.

20 Meer S, Coleman H, Altini M: Oral synovial sarcoma: a report of two cases and a review of the literature. Oral Surg Oral Med Oral Pathol Oral Radiol Endod 2003;96:306-315.

-21 Fisher C: Immunohistochemistry in diagnosis of soft tissue tumours. Histopathology 2011;58:1001-1012.

-22 Carbone A, Gloghini A, Rinaldo A, Devaney KO, Tubbs R, Ferlito A: True identity by immunohistochemistry and molecular morphology of undifferentiated malignancies of the head and neck. Head Neck 2009;31:949-961.

23 Synovial sarcoma. http://e-immunohistochemistry.info/web/synovial_sarcoma.htm.

-24 Foo WC, Cruise MW, Wick MR, Hornick JL: Immunohistochemical staining for TLE1 distinguishes synovial sarcoma from histologic mimics. Am J Clin Pathol 2011;135:839-844. 